\title{
BMJ Open The boundaries of mild chronic obstructive pulmonary disease (COPD): design of the searching clinical COPD onset (SOON) study
}

\author{
Gonzalo Labarca, ${ }^{1,2}$ Andrea Bustamante, ${ }^{3}$ Gonzalo Valdivia, ${ }^{4}$ Rodrigo Díaz, ${ }^{3}$ \\ Álvaro Huete, ${ }^{5}$ Paul Mac Nab, ${ }^{6}$ Laura Mendoza, ${ }^{7}$ Jaime Leppe, ${ }^{8}$ Carmen Lisboa, ${ }^{3}$ \\ Fernando Saldías, ${ }^{3}$ Orlando Díaz ${ }^{3,9}$
}

To cite: Labarca G,

Bustamante A, Valdivia G, et al. The boundaries of mild chronic obstructive pulmonary disease (COPD): design of the searching clinical COPD onset (SOON) study. BMJ Open 2017;7:e015731. doi:10.1136/ bmjopen-2016-015731

- Prepublication history and additional material for this paper are available online. To view these files please visit the journal online (http://dx.doi. org/10.1136/bmjopen-2016015731).

Received 23 December 2016 Revised 25 May 2017 Accepted 29 June 2017

CrossMark

For numbered affiliations see end of article.

Correspondence to

Dr Orlando Díaz;

odiazpat@gmail.com

\begin{abstract}
Introduction Clinical onset of chronic obstructive pulmonary disease (COPD) is the point at which the disease is first identifiable by physicians. It is a poorly defined stage which seems to include both mild spirometric and non-spirometric disease, and could be described as early grade COPD, for practical purposes. While dyspnoea; chronic bronchitis and CT imaging evidence of emphysema and airway disease may be present very early, the lone significance of dyspnoea, the most relevant symptom in COPD in identifying these individuals, has been scarcely assessed. The Searching Clinical COPD Onset (SOON) Study was designed primarily to detect clinical, physiological and structural differences between dyspnoeic and non-dyspnoeic individuals with early grade COPD. It is hypothesised that presence of dyspnoea in early disease may identify a subtype of individuals with reduced exercise capacity, notwithstanding of their spirometry results. In addition, dyspnoeic individuals will share worse quality of life, lower physical activity, greater lung hyperinflation greater emphysema and airway thickness and reduced peripheral muscle mass than their non-dyspnoeic counterpart.
\end{abstract}

Methods and analysis SOON is a monocentric study, with a cross sectional design aimed at obtaining representative samples of current or ex-smoker-adults aged $\geq 45$ and $\leq 80$ years. Two hundred and forty participants will be enrolled into four strata, according to normal spirometry or mild spirometric obstruction and presence or not of dyspnoea modified Medical Research Council score $\geq 1$. The primary outcome will be the difference between dyspnoeic and non-dyspnoeic individuals on the 6-min walk test performance, regardless of their spirometry results. To account for the confounding effect of heart failure on dyspnoea, stress echocardiography will be also performed. Secondary outcomes will include clinical (quality of life, physical activity), physiological (exercise testing) and structural characteristics (emphysema, airway disease and peripheral muscle mass by CT imaging).

Ethics and dissemination The Institutional Ethics Committee from Pontificia Universidad Católica de Chile has approved the study protocol and signed informed consent will be obtained from all participants. The findings of the trial will be disseminated through relevant
Strengths and limitations of this study

- One strength of this study is the inclusion of three subtypes of early grade chronic obstructive pulmonary disease (COPD), easily identifiable by presence of mild dyspnoea in current or ex-smokers, with or without spirometric bronchial obstruction. We have chosen dyspnoea as the clinical manifestation of symptomatic early grade disease, since dyspnoea is the most relevant symptom all over the range of the disease. Other studies used a composite of symptoms and/or CT imaging, with confounding results.

- The comparison of outcomes between symptomatic individuals with and without spirometric COPD is one of the relevant research questions presented in a recent American Thoracic Society/European Respiratory Society Statement.

- We will also measure heart function by stress echocardiography, to evaluate the possible role of undiagnosed heart failure on dyspnoea and exercise limitation in early grade COPD.

- Early grade COPD may include subtypes of disease with high-risk for greater and faster worsening over time in clinical, structural and/or physiological outcomes. After completion, another study will assess longitudinal changes in lung function in the same population.

- A potential limitation is selection bias, because the study is monocentric, non-population-based and restricted to patients able to perform exercise testing. Accordingly, the results of this study will be applicable to a relatively selected population of early grade COPD.

peer-reviewed journals and international conference presentations.

Trial registration number NCT03026439.

\section{BACKGROUND}

Chronic obstructive pulmonary disease (COPD) has a protracted course before 
clinical onset, following classical epidemiological principles of chronic disease and genetic predisposition. Clinical onset is the point at which the disease is first identifiable by physicians and could be defined either as a physiologic impairment expressed by a lone abnormal spirometric index and/or as a clinical manifestation of the disease, such as cough, phlegm, dyspnoea and exercise limitation. Consequently, clinical COPD onset may represent both mild spirometric disease, but also mild "non-spirometric COPD", an entity mainly centred on symptoms and structural changes in lung and airway CT imaging. ${ }^{12}$ In our view, the combination of both forms of disease characterise what we will describe as "early grade COPD", in line with the definition of Decramer et al. ${ }^{3}$ Please note that since many patients with non-spirometric COPD and asymptomatic mild disease will be detected in the present study by chance or because of spirometric screening indicated by their physicians, others groups should prefer to define these patients as "preclinical

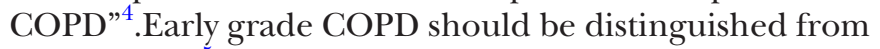
early COPD. ${ }^{5}$ Early disease denotes a time-point during the natural history of COPD, either before the disease is present or a time-point when the disease has not yet fully evolved to their clinical expression. ${ }^{6}$ Early grade COPD refers to the minimal loss of function, reflected in spirometry or symptoms, where COPD could be first diagnosed. Neither of these definitions take into account the activity of the disease, which is a concept related to the level of stimulation of the biological processes that drive disease progression. ${ }^{7}$ Longitudinal measurements of lung function will be needed to establish disease activity. In summary, early disease refers to a point in a timescale before clinical disease onset, while early grade disease refers to a minimal disease severity able to be detected. A pragmatic view of early grade COPD is described on Table 1, including three subtypes of patients and a group of smokers with normal spirometry and absence of symptoms as a control group. These groups are roughly similar to Global initiative for Chronic Obstructive Lung Disease
(GOLD) grades 0 and $1,{ }^{7}$ although further characterised by the presence or absence of dyspnoea. Please note, however, that dyspnoea cut-off value chosen to separate symptomatic from asymptomatic subjects is a modified Medical Research Council (mMRC) score $\geq 1$, in line with several recent communications, ${ }^{8-10}$ but differing from the cut-off recommended by GOLD (score $\geq 2$ ). ${ }^{11}$ Also note that GOLD 0 category, ${ }^{7}$ included in the GOLD guidelines of 2001 and currently not in use, did not comprise a dyspnoeic subtype, which is now included in light of new evidence pointing out at their potential relevance. ${ }^{212}$

The first subtype of table 1 (Group 2) has been reported by Woodruff $e t a l^{2}$ on a large sample of smokers with normal spirometry who have chronic respiratory symptoms, exacerbations, lower than normal exercise tolerance and CT imaging evidence of bronchiolitis. These results complement previous findings of another large study from Regan et al $^{1}$ showing that more than $50 \%$ of symptomatic smokers with normal spirometry have respiratory-related impairment and evidence of emphysema on CT imaging. Woodruff $e t a l^{2}$ used the COPD Assessment Test (CAT) questionnaire to define symptoms ${ }^{13}$ and found that both respiratory (cough and sputum) and less specific symptoms (dyspnoea, wheezing, activity limitation and energy level) were equally distributed among symptomatic smokers regardless of the presence of spirometric COPD. However, although CAT is intended to be specific for COPD,$^{13}$ most of its domains may reflect concomitant respiratory (asthma and bronchiectasis) and/or non-respiratory diseases (heart failure, ischaemic heart disease, obesity and depression). ${ }^{14}$ In contrast, Regan $e t$ $a l^{1}$ measured seven 'respiratory-related impairments' and found one or more to be present in $54 \%$ of patients. Three of these impairments could be considered rather specific of COPD, like CT percentage of emphysema $>5 \%$ and gas trapping $>20 \%$ and SGRQ total score $>25$. Nevertheless, four impairments (chronic bronchitis, modified Medical Research Council (mMRC) dyspnoea score $\geq 2$, exacerbations and 6-min walk distance $<350 \mathrm{~m}$ ) are non-specific as

Table 1 Enrolment strata by dyspnoea and lung function

$\begin{array}{llll}\text { Group } 1 & \text { Group 2 } & \text { Group } 3 & \text { Group } 4\end{array}$

$\begin{array}{lll}\text { Asymptomatic smokers Symptomatic smokers } & \begin{array}{l}\text { Asymptomatic mild } \\ \text { COPD }\end{array} & \begin{array}{l}\text { Symptom } \\ \text { COPD }\end{array}\end{array}$

\begin{tabular}{|c|c|c|c|c|}
\hline Smoking status & $>10$ pack-years & $>10$ pack-years & $>10$ pack-years & $>10$ pack-years \\
\hline Dyspnoea mMRC score & 0 & $\geq 1$ & 0 & $\geq 1$ \\
\hline Lung function assessment & Postbronchodilator & Postbronchodilator & Postbronchodilator & Postbronchodilator \\
\hline $\mathrm{FEV}_{1} / \mathrm{FVC}$ ratio criteria & $\mathrm{FEV}_{1} / \mathrm{FVC} \geq 0.7$ & $\mathrm{FEV}_{1} / \mathrm{FVC} \geq 0.7$ & $\mathrm{FEV}_{1} / \mathrm{FVC}<0.7$ & $\mathrm{FEV}_{1} / \mathrm{FVC}<0.7$ \\
\hline Other spirometric criteria & FVC $>80 \%$ pred & FVC $>80 \%$ pred & $\mathrm{FEV}_{1}>80 \%$ pred & $\mathrm{FEV}_{1}>80 \%$ pred \\
\hline Sample size & $\mathrm{n}=120$ & & $\mathrm{n}=120$ & \\
\hline $\begin{array}{l}\text { Sample size by groups } \\
\text { (approximate) }\end{array}$ & $\approx 50 \%$ & $\approx 50 \%$ & $\approx 50 \%$ & $\approx 50 \%$ \\
\hline
\end{tabular}

For simplicity, we have excluded from this schema the Global Initiative for Chronic Obstructive Lung Disease unclassified group. COPD, chronic obstructive pulmonary disease; FEV $_{1}$, forced expiratory volume in $1 \mathrm{~s}$; FVC, forced vital capacity; LLN, lower limit of normal; mMRC, modified Medial Research Council dyspnoea score. 
they may be partly or fully explained by comorbidities like gastro-oesophageal reflux disease, rhinosinusitis (upper airway cough syndrome/postnasal drip), obesity or heart failure, among others. In fact, retrospective data suggest that patients with COPD and comorbid conditions may have greater risk for having symptoms, rather than those without comorbidity. ${ }^{1516}$

The second subtype (Group 3), that is, early grade smoking-induced lung disease with mildly abnormal spirometry but absence of symptoms (dyspnoea mMRC score equal to zero; absence of chronic cough and/or chronic expectoration) has been also described. ${ }^{1718}$ However, there is conflicting evidence about lung function and exercise performance in this group of patients. Two studies suggest that patients with mild non-dyspnoeic spirometric disease may include individuals with normal lung function and 6-min walk test performance ${ }^{18}$ and subjects with resting lung hyperinflation, reduced diffusion capacity of the lung for carbon monoxide (DLCO) and slightly increased cycle-exercise-induced dyspnoea. ${ }^{17}$

The third subtype (Group 4) corresponds to symptomatic mild COPD. These patients have significant emphysema and airway thickness, lower DLCO, exercise-induced arterial desaturation and reduced 6-min walking distance. ${ }^{18} 19$ In addition, during incremental cycle-exercise they exhibit increased ventilatory demand, lung hyperinflation and greater exertional dyspnoea than smoker controls. ${ }^{20}$

We consider that defining early grade COPD subtypes by clinical findings is the first step in pointing out a highrisk early grade disease group. If this high-risk group exists, it should exhibit in prospective studies greater and faster deterioration in symptoms, lung and/or peripheral muscle physiology and structure. Possible benefits in identifying such early grade COPD subtypes will depend on finding specific anomalies that could define the need of early interventions in terms, for instance, of smoking cessation, bronchodilation or pulmonary rehabilitation. And even though there are no established therapies to treat lung function decline, early identification of these subjects also allows prognostic information and perhaps targeting novel therapies.

\section{AIMS}

This study intends to identify three early grade COPD subtypes defined by symptoms (dyspnoea) and spirometric airway obstruction (table 1) using differences in exercise capacity as the primary outcome. As secondary outcomes, we will intend to separate these groups by means of differences in clinical (quality of life, physical activity), physiological (exercise testing) and structural characteristics (emphysema, airway disease and peripheral muscle mass by CT imaging). Future analyses are planned to evaluate longitudinal deterioration in these clinical, physiological and structural characteristics. Potential influence of obesity and undiagnosed heart failure on dyspnoea and thus, on exercise capacity, will be explored within the three subtypes.

\section{HYPOTHESES}

For the present proposal, we will use dyspnoea to define a symptomatic subject. We hypothesise that dyspnoeic individuals notwithstanding of their spirometry results should share some clinical, structural and physiologic abnormalities. In particular, we expect that the two dyspnoeic groups with and without spirometric bronchial obstruction (Groups 2 and 4 in table 1) exhibit reduced exercise capacity, in addition to worse quality of life, lower physical activity, greater lung hyperinflation, greater emphysema and airway thickness and reduced peripheral muscle mass than their asymptomatic counterpart (Groups 1 and 3 in table 1).

\section{METHODS}

Details on clinical definitions, inclusion/exclusion criteria and measurements are available in the online supplementary file 1 .

\section{Study design}

SOON has a cross-sectional design aimed at obtaining representative samples of adults between 45 and 80 years. Two hundred and forty participants will be enrolled into four strata as shown in table 1 . Study subjects will be recruited from the outpatient clinics and the pulmonary function labs at the Pontifical Catholic University of Chile Health Network by means of physician referral, advertisement in clinical areas or self-referral at the study centre. The Institutional Ethics Committee approved the study protocol and signed informed consent will be obtained from all participants.

\section{Definitions}

Mild COPD will be defined according to a fixed forced expiratory volume in $1 \mathrm{~s}\left(\mathrm{FEV}_{1}\right) /$ forced vital capacity (FVC) ratio $<0.70$ and a $\mathrm{FEV}_{1} \geq 80 \%$ of predicted value. We are aware that such definition will result in more frequent diagnosis of COPD in the elderly ${ }^{21}$ compared to a cut-off using the lower limit of normal (LLN) values for $\mathrm{FEV}_{1} / \mathrm{FVC}^{22}$ However, LLN values are highly dependent on the choice of valid reference equations using post-bronchodilator $\mathrm{FEV}_{1}$, and neither longitudinal studies validating the use of the LLN, nor studies using reference equations in populations where smoking is not the major cause of COPD are available. Under diagnosis will be unlikely because individuals younger than 45 years will be excluded.$^{23}$ For the purposes of the present study, we have defined "early grade disease" when former or ex-smoker-adults: a) complain of dyspnoea but have normal spirometry; b) complain of dyspnoea and have mild bronchial obstruction; and, c) have mild bronchial obstruction without dyspnoea. 


\section{Inclusion and exclusion criteria}

Patients must be $45-80$ years of age, have a smoking history of $>10$ pack-years and meet lung function criteria as shown in table 1 . Patients will be excluded if they have a significant disease other than COPD, cognitive disorders, conditions precluding them from exercise, recent diagnosis of cancer, history of diseases or treatments likely to interfere with interpretation of study tests, body mass index $>40 \mathrm{~kg} / \mathrm{m}^{2}$ and diagnosis of unstable cardiovascular disease. Lung surgery and metal in the chest that may affect the chest CT interpretation are also exclusionary. Online supplementary table contains the complete list of exclusion criteria. The presence of usual comorbidities, such as essential hypertension, diabetes, osteoporosis, hypothyroidism, under proper medical control and obesity, excluding extreme obesity, will not be considered an exclusion criterion.

\section{Measurements}

Assessment will include anthropometry, clinical history, health-related quality of life, conventional haematology and blood chemistry analysis, physical activity, lung physiology, lung and mid-tight CT imaging, stress echocardiography and exercise testing (table 2). For lung physiology, subjects will undergo spirometry, static lung volumes and DLCO. For lung, airway and peripheral muscle structure CT imaging will be assessed with volumetric chest CT scan at full inspiration and right

\section{Table 2 Outcome measurements}

\begin{tabular}{ll}
\hline Measurement & Description \\
\hline Health measurements & \\
Depression questionnaire & Centre for Epidemiologic Studies of Depression scale \\
\hline $\begin{array}{l}\text { Anxiety questionnaire } \\
\text { Health status }\end{array}$ & Anxiety subscale of the Hospital Anxiety and Depression Scale \\
Dyspnoea & Saint George Respiratory Questionnaire, COPD Assessment Test \\
Haematology and blood chemistry analyses & Modified Medial Research Council dyspnoea scale \\
\hline $\begin{array}{l}\text { Complete blood count } \\
\text { Comprehensive metabolic panel }\end{array}$ & $\begin{array}{l}\text { Red and white blood cells, platelets } \\
\text { Glucose, calcium, albumin and total blood protein, blood urea nitrogen, } \\
\text { creatinine, alkaline phosphatase, alanine amino transferase, aspartate amino } \\
\text { transferase and bilirubin }\end{array}$ \\
Lipid panel & $\begin{array}{l}\text { Total cholesterol, high-density lipoproteins cholesterol, low-density } \\
\text { lipoproteins cholesterol and triglycerides }\end{array}$
\end{tabular}

Lung function

Spirometry pre-postbronchodilator $\mathrm{FEV}_{1}$, FVC, $\mathrm{FEV}_{1} / \mathrm{FVC}, \mathrm{IC}$, reversibility

Pulmonary plethysmography RV, TLC, FRC

Diffusion capacity of the lung for carbon monoxide

Heart function

$\begin{array}{ll}\text { Resting echocardiography } & \text { Measurement of diastolic and systolic function } \\ \text { Stress echocardiography } & \text { Measurement of systolic function and potential myocardial ischemia } \\ \text { Chest CT } & \text { Measurement of airway characteristics } \\ & \text { Quantification of emphysema } \\ \text { Mid-tight CT } & \text { Measurements of right mid-tight area } \\ \text { Exercise capacity } & \text { Supervised, encouraged 6-min walk test }\end{array}$

Cardiopulmonary exercise test on a cycle ergometer

Peak $\mathrm{VO}_{2}, \mathrm{VCO}_{2}$, VE Symptom-limited incremental cycle exercise test

Iso-time and iso-work measurements Constant work rate cycle endurance test

Physical activity

Triaxial accelerometer measurement

\section{Step count}

Spent physical activity time per day

Physical activity level

COPD, chronic obstructive pulmonary disease; IC, inspiratory capacity; $F_{E V}$, forced expiratory volume in $1 \mathrm{~s}$; FRC, functional residual capacity; FVC, forced vital capacity; RV, residual volume; TLC, total lung capacity; $\mathrm{VCO}_{2}$, carbon dioxide production; VE, minute ventilation; $\mathrm{VO}_{2}$, oxygen consumption. 
mid-tight CT. At rest and end-exercise, heart function will be assessed by stress echocardiography. Exercise performance will be evaluated with the 6-min walk test and with symptom-limited incremental and constant workload cycle exercise testing. A summary of full protocol measures is shown in table 2 and operative definition is reported in online supplementary appendix 1 .

\section{STATISTICAL ANALYSIS \\ Outcomes}

The primary outcome will be the difference between dyspnoeic and non-dyspnoeic individuals on the 6-min walk test performance, regardless of their spirometry results.

Secondary outcomes will include differences on anthropometry, clinical history, health-related quality of life, conventional haematology and blood chemistry analysis, lung physiology, lung and mid-tight CT imaging, stress echocardiography and exercise testing.

\section{Analysis}

Between-group comparisons will be analysed using $\chi^{2}$, Fisher's test and one-way analysis of variance for categorical and continuous variables, respectively.

Main differences between dyspnoeic groups 2 and 3 (table 1) will be assessed first using a univariate model and later on a multivariate model taking into account potential confounders. In order to understand the influence of obesity and systolic or diastolic heart failure on dyspnoea, a stratified analysis will be performed testing for potential confounding or interaction effects. Data will be reported with OR with a 95\% CI. All data will be processed using SPSS software version 15.0 (Chicago, Illinois, USA).

\section{Sample size}

A sample size of at least 52 subjects per group provide enough power $(80 \%)$ to detect a significant difference (95\% CI or alpha 0.05$)$ in the 6-min walk test among symptomatic and asymptomatic participants, based on a conservative relevant difference in walking distance of $50 \mathrm{~m}$ with a common SD of $110 \mathrm{~m}$. Such difference was found when comparing symptomatic and asymptomatic subjects with normal spirometry, ${ }^{2}$ but may be an underestimation in patients with mild spirometric COPD,${ }^{18}$ where the difference between symptomatic and asymptomatic patients was $100 \mathrm{~m}$. Forestalling a participant loss rate of 20\%, 60 patients will be included in each group.

\section{DISCUSSION}

In this study, we will attempt to identify early grade COPD subtypes, according to the presence of dyspnoea among smokers with and without spirometric bronchial obstruction.

The first subset of patients (Group 2 in table 1) is grossly similar to the 'Stage 0', labelled so by the 2001 GOLD Report. ${ }^{7}$ However, GOLD 0 was defined by the sole presence of chronic cough and phlegm, usually referred to as chronic bronchitis, with normal spirometry. We are widening the definition to include subjects with dyspnoea independently of the presence of chronic bronchitis. Previous studies have shown that broadening the GOLD stage 0 definition to chronic bronchitis and/or dyspnoea increased the risk of dead for this grade. ${ }^{24-26}$ Other studies have suggested that the presence of chronic $\operatorname{cough}^{27-29}$ but not dyspnoea ${ }^{28}$ identified individuals with high risk of future occurrence of COPD. Nevertheless, chronic bronchitis is not necessarily a chronic condition and can vary over time, ${ }^{28}{ }^{30}$ the main determinant of this variation being smoking status. ${ }^{30}$ Development or resolution of chronic bronchitis does not seem to relate directly with worsening lung function, such that lung function decline has been similar in patients with and without chronic bronchitis. ${ }^{3031}$ Thus, while it appears that chronic bronchitis may be a marker of future COPD development and probably modulate early phases of COPD development, dyspnoea is more likely a manifestation of disease already present. It remains to be proven, however, if this form of early grade disease corresponds to COPD or to other smoking-related lung disease.

The second subtype (Group 3 in table 1) includes patients with abnormal spirometry but absence of dyspnoea. As already mentioned, two studies have found conflicting results regarding lung function, CT imaging emphysema, CT airways structure, and exercise performance in this group of patients. Soumagne $e t$ al, ${ }^{17}$ using $\mathrm{FEV}_{1} / \mathrm{FVC}$ below the lower limit of normal (LLN) to define mild COPD, found resting hyperinflation, lower DLCO, reduced peak oxygen consumption $\left(\mathrm{VO}_{2}\right)$ and increased cycle exercise-induced dyspnoea compared with smoker controls. On the contrary, using $\mathrm{FEV}_{1} / \mathrm{FVC}<0.70$, Díaz $e t a l^{18}$ did not find differences in lung function, quality of life, emphysema, bronchial wall thickness or exercise capacity between asymptomatic mild COPD and smoker controls. Smoker controls in both studies are well described by asymptomatic smokers (Group 1 ) of table 1 . Although asymptomatic mild COPD patients from the study of Diaz et $a l^{18}$ had greater mean $\mathrm{FEV}_{1} / \mathrm{FVC}(68 \%$ vs $61 \%$ ) and may thus represent normal people misclassified by using fixed spirometric indexes, a posthoc analysis of their data have shown that $72 \%$ of these patients also

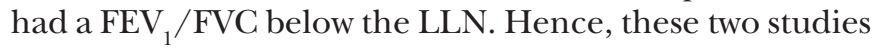
suggest that patients with mild asymptomatic spirometric disease may represent a continuous spectrum from complete absence to slightly increased cycle-exercise-induced dyspnoea. Such variability has been also shown by Gagnon $e t ~ a l .{ }^{32}$ In the present study, we will evaluate a larger sample to disentangle these inconsistencies.

The third subset of patients (Group 4 in table 1) is more easily identifiable, since it belongs to GOLD group B-spirometric grade $1 .{ }^{11}$ The only difference is that we will use a dyspnoea mMRC cut-off score $\geq 1$, at variance of the GOLD recommendation (mMRC score $\geq 2$ ). ${ }^{11}$ We have already pointed out that in our opinion the dyspnoea cut-off which best separates symptomatic from 
asymptomatic subjects is a mMRC score $\geq 1$, because several communications indicate that cut off of mMRC score $\geq 1$ and CAT score $\geq 10$ are equivalent in separating low from high-symptom patients ${ }^{8933}$ and that this cut-off correlates best with CAT $\geq 10^{8-10}$ than the criteria recommended by GOLD (score $\geq 2$ ). ${ }^{11}$ Moreover, at least two studies have found reduced physical activity from dyspnoea mMRC score 1 or greater, independently of disease severity. ${ }^{35}$ The importance of mMRC dyspnoea $\geq 1$ as an inflection point to differentiate patients from smoker subjects without COPD in terms of reduced physical activity has also been highlighted in another study where only dyspnoeic COPD patient's exhibited reduced physical activity, while non-dyspnoeic individuals had similar physical activity levels than controls. ${ }^{36}$ We are confident, however, that future studies will properly define which thresholds are the best to make CAT and MMRC equivalent, refining current recommendations.

The true prevalence of Groups 2 and 4 is poorly known. Concerning Group 4, at least three studies have found dyspnoea mMRC score $\geq 1$ in approximately $45 \%-50 \%$ of patients with mild COPD. ${ }^{18}{ }^{37} 38 \mathrm{~A}$ similar proportion $(43 \%)$ reported dyspnoea mMRC $\geq 1$ in mild-to-moderate COPD patients from the Lung Health Study. ${ }^{39}$ The prevalence of higher dyspnoea scores $(\mathrm{mMRC} \geq 2)$ in mild COPD is apparently broader, ranging from $9 \%$ to 22\%. ${ }^{140} 41$ The distribution of dyspnoea scores among Group 2 is even less well known. In the COPDGene Study, prevalence of $\mathrm{mMRC} \geq 2$ was $24 \%,{ }^{1}$ but we have found no data regarding prevalence of milder dyspnoea, that is, $\mathrm{mMRC}=1$. Therefore, a potential risk of the SOON study is under-representation of Group 2 (dyspnoeic GOLD 0 ).

Groups 2 and 4 probably represent high-risk individuals with active disease, but at different grades of disease severity, which in future follow-up could exhibit faster deterioration of clinical, structural and physiological characteristics than low-risk individuals. In the SAPALDIA cohort, for instance, subjects with symptomatic mild COPD had a faster rate of decline in lung function, greater respiratory resource utilisation and worse quality of life than asymptomatic mild COPD patients and asymptomatic subjects with normal lung function. ${ }^{42}$ Similar information from Group 2 (dyspnoeic GOLD 0) is lacking. As pointed out by Rodriguez-Roisin et al. ${ }^{43}$ "the dilemma remains as to whether we are confronted with an early phase of what will become COPD in the traditional sense or a separate smoking-related condition without progression to spirometric COPD" ${ }^{43}$

\section{Perpectives}

The present study was designed primarily to detect clinical, physiological and structural differences between dyspnoeic and non-dyspnoeic individuals with early grade COPD. Disease progression at early grade COPD is currently unpredictable, but we suspect that individuals at greater risk of accelerated lung function decline may be singled out. It is hypothesized that dyspnoea may identify those individuals. Consequently, after completion, another study has been planned to evaluate longitudinal changes in lung function in the same population.

\section{Author affiliations}

${ }^{1}$ Faculty of Medicine, Universidad San Sebastián, Concepción, Concepción, Chile 2Division of Internal Medicine, Complejo Asistencial Víctor Ríos Ruiz, Los Ángeles, Chile

${ }^{3}$ Department of Pulmonary Diseases, Faculty of Medicine, Pontifical Catholic University of Chile, Santiago, Chile

${ }^{4}$ Department of Public Health, Faculty of Medicine, Pontifical Catholic University of Chile, Santiago, Chile

${ }^{5}$ Department Radiology, Faculty of Medicine, Pontifical Catholic University of Chile, Santiago, Chile

${ }^{6}$ Department of Cardiovascular Diseases, Faculty of Medicine, Pontifical Catholic University of Chile, Santiago, Chile

${ }^{7}$ Section of Pulmonary Medicine, Department of Medicine, Universidad de Chile, Santiago, Chile

${ }^{8}$ School of Physical Therapy, Facultad de Medicina Clínica Alemana, Universidad del Desarrollo, Santiago, Chile

${ }^{9}$ Department of Critical Care, Faculty of Medicine, Pontifical Catholic University of Chile, Santiago, Chile

Contributors OD: Mentor, conception and design of the study; recruitment of patients; data collection; analysis and interpretation and drafting the manuscript for important intellectual content, register in clinical trials and correspondence author. GL: Conception and design of the study; recruitment of patients; analysis and interpretation and drafting the manuscript for important intellectual content. $\mathrm{AB}$ : Conception and design of the study; recruitment of patients; drafting the manuscript for important intellectual content. CL: Analysis and interpretation and drafting the manuscript for important intellectual content. JL: Recruitment of patients; data analysis and interpretation. RD: Data collection; data analysis and interpretation. FS: Conception and design of the study; recruitment of patients; analysis and interpretation and drafting the manuscript for important intellectual content. AH: Conception and design of the study; data analysis and interpretation. PMN: Conception and design of the study; data collection; data analysis and interpretation. GV: Conception and design of the study; analysis and interpretation and drafting the manuscript for important intellectual content. LM: Recruitment of patients; data collection; drafting the manuscript for important intellectual content.

Funding Grant by National Fund for Scientific \& Technological Development (FONDECYT) number \# 1141108.

Competing interests None declared.

Patient consent Obtained.

Ethics approval Pontificia Universidad Catolica de Chile.

Provenance and peer review Not commissioned; externally peer reviewed.

Open Access This is an Open Access article distributed in accordance with the Creative Commons Attribution Non Commercial (CC BY-NC 4.0) license, which permits others to distribute, remix, adapt, build upon this work non-commercially, and license their derivative works on different terms, provided the original work is properly cited and the use is non-commercial. See: http://creativecommons.org/ licenses/by-nc/4.0/

(c) Article author(s) (or their employer(s) unless otherwise stated in the text of the article) 2017. All rights reserved. No commercial use is permitted unless otherwise expressly granted.

\section{REFERENCES}

1. Regan EA, Lynch DA, Curran-Everett D, et al. Clinical and radiologic disease in smokers with normal spirometry. JAMA Intern Med 2015;175:1539-49.

2. Woodruff PG, Barr RG, Bleecker E, et al. Clinical significance of symptoms in smokers with preserved pulmonary function. $N$ Engl J Med 2016;374:1811-21.

3. Decramer M, Miravitlles M, Price D, et al. New horizons in early stage COPD--improving knowledge, detection and treatment. Respir Med 2011;105:1576-87.

4. Van Remoortel H, Hornikx M, Langer D, et al. Risk factors and comorbidities in the preclinical stages of chronic obstructive pulmonary disease. Am J Respir Crit Care Med 2014;189:30-8. 
5. Agustí A, Celli B. Avoiding confusion in COPD: from risk factors to phenotypes to measures of disease characterisation. Eur Respir $J$ 2011;38:749-51.

6. Rennard SI, Drummond MB. Early chronic obstructive pulmonary disease: definition, assessment, and prevention. Lancet 2015;385:1778-88.

7. Pauwels RA, Buist AS, Calverley PM, et al. Global strategy for the diagnosis, management, and prevention of chronic obstructive pulmonary disease. NHLBI/WHO global Initiative for chronic obstructive lung disease (GOLD) Workshop summary. Am J Respir Crit Care Med 2001;163:1256-76.

8. Kim S, Oh J, Kim Yl, et al. Differences in classification of COPD group using COPD assessment test (CAT) or modified Medical Research Council (mMRC) dyspnea scores: a cross-sectional analyses. BMC Pulm Med 2013;13:35.

9. Jones PW, Adamek L, Nadeau G, et al. Comparisons of health status scores with MRC grades in COPD: implications for the GOLD 2011 classification. Eur Respir J 2013;42:647-54.

10. Han MK, Muellerova H, Curran-Everett D, et al. GOLD 2011 disease severity classification in COPDGene: a prospective cohort study. Lancet Respir Med 2013;1:43-50.

11. Vestbo J, Hurd SS, Agustí AG, et al. Global strategy for the diagnosis, management, and prevention of chronic obstructive pulmonary disease: gold executive summary. Am J Respir Crit Care Med 2013;187:347-65.

12. Oelsner EC, Hoffman EA, Folsom AR, et al. Association between emphysema-like lung on cardiac computed tomography and mortality in persons without airflow obstruction: a cohort study. Ann Intern Med 2014;161:863-73.

13. Karloh M, Fleig Mayer A, Maurici R, et al. The COPD Assessment Test: what do we Know so Far?: a systematic review and MetaAnalysis about clinical outcomes prediction and classification of patients Into GOLD stages. Chest 2016;149:413-25.

14. Fabbri LM. Smoking, Not COPD, as the Disease. N Engl J Med 2016;374:1885-6.

15. Agusti A, Edwards LD, Celli B, et al.Characteristics, stability and outcomes of the 2011 GOLD COPD groups in the ECLIPSE cohort. Eur Respir J 2013;42:636-46.

16. Agusti A, Hurd S, Jones P, et al. FAQs about the GOLD 2011 assessment proposal of COPD: a comparative analysis of four different cohorts. Eur Respir J 2013;42:1391-401.

17. Soumagne T, Laveneziana P, Veil-Picard M, et al. Asymptomatic subjects with airway obstruction have significant impairment at exercise. Thorax 2016;71:804-11.

18. Díaz AA, Morales A, Díaz JC, et al. CT and physiologic determinants of dyspnea and exercise capacity during the six-minute walk test in mild COPD. Respir Med 2013;107:570-9.

19. Kirby M, Owrangi A, Svenningsen S, et al. On the role of abnormal $\mathrm{DL}(\mathrm{CO})$ in ex-smokers without airflow limitation: symptoms, exercise capacity and hyperpolarised helium-3 MRI. Thorax 2013;68:752-9.

20. Ofir D, Laveneziana P, Webb KA, et al. Mechanisms of dyspnea during cycle exercise in symptomatic patients with GOLD stage I chronic obstructive pulmonary disease. Am J Respir Crit Care Med 2008;177:622-9.

21. Hardie JA, Buist AS, Vollmer WM, et al. Risk of over-diagnosis of COPD in asymptomatic elderly never-smokers. Eur Respir J 2002;20:1117-22.

22. Mohamed Hoesein FA, Zanen P, Lammers JW. Lower limit of normal or FEV1/FVC < 0.70 in diagnosing COPD: an evidence-based review. Respir Med 2011;105:907-15.

23. Cerveri I, Corsico AG, Accordini S, et al. Underestimation of airflow obstruction among young adults using FEV1/FVC $<70 \%$ as a fixed cut-off: a longitudinal evaluation of clinical and functional outcomes. Thorax 2008;63:1040-5.
24. Stavem K, Sandvik L, Erikssen J. Can global initiative for chronic obstructive lung disease stage 0 provide prognostic information on long-term mortality in men? Chest 2006;130:318-25.

25. Mannino DM, Doherty DE, Sonia Buist A. Global Initiative on obstructive lung disease (GOLD) classification of lung disease and mortality: findings from the Atherosclerosis risk in communities (ARIC) study. Respir Med 2006;100:115-22.

26. Kohansal R, Martinez-Camblor P, Agustí A, et al. The natural history of chronic airflow obstruction revisited: an analysis of the Framingham offspring cohort. Am J Respir Crit Care Med 2009;180:3-10.

27. Guerra S, Sherrill DL, Venker C, et al. Chronic bronchitis before age 50 years predicts incident airflow limitation and mortality risk. Thorax 2009;64:894-900.

28. de Marco R, Accordini S, Cerveri I, et al. Incidence of chronic obstructive pulmonary disease in a cohort of young adults according to the presence of chronic cough and phlegm. Am J Respir Crit Care Med 2007;175:32-9.

29. Allinson JP, Hardy R, Donaldson GC, et al. The presence of chronic mucus hypersecretion across adult life in relation to chronic obstructive pulmonary Disease Development. Am J Respir Crit Care Med 2016;193:662-72.

30. Kim V, Zhao H, Boriek AM, et al. Persistent and newly developed chronic bronchitis are associated with worse outcomes in chronic obstructive pulmonary disease. Ann Am Thorac Soc 2016;13:1016-25.

31. Vestbo J?rgen, Edwards LD, Scanlon PD, et al. Changes in forced expiratory volume in 1 second over Time in COPD. N Engl J Med Overseas Ed 2011;365:1184-92.

32. Gagnon P, Casaburi R, Saey D, et al. Cluster analysis in patients with GOLD 1 chronic obstructive pulmonary disease. PLoS One 2015;10:e0123626.

33. Han J, Dai L, Zhong N, et al. Breathlessness or health status in chronic obstructive pulmonary disease: the impact of different definitions. COPD 2015;12:115-25.

34. Parada A, Klaassen J, Lisboa C, et al. Reducción de la actividad física en pacientes con enfermedad pulmonar obstructiva crónica. Rev Med Chil 2011;139:1562-72.

35. Watz H, Waschki B, Meyer T, et al. Physical activity in patients with COPD. Eur Respir J 2009;33:262-72.

36. Van Remoortel H, Hornikx M, Demeyer $\mathrm{H}$, et al. Daily physical activity in subjects with newly diagnosed COPD. Thorax 2013;68:962-3.

37. Bednarek M, Maciejewski J, Wozniak M, et al. Prevalence, severity and underdiagnosis of COPD in the primary care setting. Thorax 2008;63:402-7.

38. Montes de Oca M, Tálamo C, Halbert RJ, et al. Health status perception and airflow obstruction in five latin american cities: the PLATINO study. Respir Med 2009;103:1376-82.

39. Buist AS, Connett JE, Miller RD, et al. Chronic Obstructive Pulmonary Disease Early Intervention Trial (Lung Health Study). Baseline characteristics of randomized participants. Chest 1993;103:1863-72.

40. Steuten LM, Creutzberg EC, Vrijhoef HJ, et al. COPD as a multicomponent disease: inventory of dyspnoea, underweight, obesity and fat free mass depletion in primary care. Prim Care Respir J 2006;15:84-91.

41. Lange P, Marott JL, Vestbo J, et al. Prediction of the clinical course of chronic obstructive pulmonary disease, using the new GOLD classification: a study of the general population. Am J Respir Crit Care Med 2012;186:975-81.

42. Bridevaux PO, Gerbase MW, Probst-Hensch NM, et al. Long-term decline in lung function, utilisation of care and quality of life in modified GOLD stage 1 COPD. Thorax 2008;63:768-74.

43. Rodriguez-Roisin R, Han MK, Vestbo J, et al. Chronic Respiratory Symptoms with Normal Spirometry. A Reliable Clinical Entity? Am J Respir Crit Care Med 2017;195:17-22. 